\title{
Enunciado emotivo e impacto sociointerativo: um estudo de caso em contexto francófono
}

\section{Emotional Statement and Socio-Interactive Impact: A Case Study in Francophone Context}

Ruth de Oliveira*

*University of Cape Town (UCT), Cidade do Cabo / África do Sul ruth.deoliveira@uct.ac.za

https://orcid.org/0000-0003-0100-0259

RESUMO: Este trabalho é uma contribuição ao estudo das emoções no discurso e seu impacto sociointerativo, tomando as emoções como constitutivas das relações de troca, numa abordagem discursiva. A partir da análise de interações verbais observadas e repertoriadas em contexto francófono (DE OLIVEIRA, 2014, 2015): (i) associamos a deslocação pronominal à direita (LAMBRECHT, 1994; NØLKE, 1997) ao sentimento de aborrecimento do locutor (PLANTIN; DOURY; TRAVERSO, 2000; PLANTIN, 2011); (ii) mostramos de que maneira esse comportamento linguístico (global $\rightarrow$ particular) é incompatível com o contrato de cooperação (GRICE, 1975); e (iii) postulamos sobre as consequências negativas desse comportamento nas relações entre os participantes das trocas (JOBERT, 2010; KERBRATORECCHIONI, 2010). As marcas linguísticas da presença do sujeito discursivo possibilitam especular sobre a imagem que ele dá de si (BROWN; LEVINSON, 1987). Por fundamentar-se na linguística aplicada, esta proposta visa atuar na conscientização dos locutores sobre o poder e o impacto da linguagem nas práticas cotidianas.

PALAVRAS-CHAVE: enunciado emotivo; argumentação; impolidez linguística; teoria das faces; contrato de cooperação.

ABSTRACT: This work is a contribution to the study of emotions in discourse and its socio-interative impact, considering emotions as constitutive of exchanges, in a discoursive approach. From the analysis of verbal interactions observed and assimilated in a French-speaking context (DE OLIVEIRA 2014, 2015), (i) we associate the right dislocation construction (LAMBRECHT 1994, NØLKE 1997) with the speaker's annoyance (PLANTIN, DOURY, TRAVERSO 2000, PLANTIN 2011); (ii) demonstrate how this linguistic behavior (global $\rightarrow$ particular) is incompatible with the principle of cooperation (GRICE 1975), and (iii) postulate the negative consequences of this behavior 
in the relations between the participants of exchanges (JOUBERT 2010, KERBRAT-ORECCHIONI 2010). The linguistic markers of the discursive subject's presence make it possible to speculate about the image he gives of himself (BROWN and LEVINSON 1987). Primarily based on Applied Linguistics, this proposal aims to promote the awareness of speakers about the power and the impact of language in everyday practices.

KEYWORDS: emotional statement; argumentation; linguistic impoliteness; face theory; cooperation contract.

\section{Introdução}

Perante outras disciplinas das ciências humanas e sociais, pode a noção de emoções ser objeto de um estudo especificamente linguageiro? Para Patrick Charaudeau (2003, p. 23), essa é a primeira questão que um analista do discurso se coloca. Segundo o autor, uma resposta positiva implica a delimitação do quadro de tratamento no qual a noção de emoção se insere, assim como na descrição das condições do seu surgimento e funcionamento. Por outro lado, Charaudeau argumenta que embora se distinguindo (entre outras disciplinas) da psicologia e da sociologia, "a análise do discurso precisa delas, na medida em que suas análises evidenciam os mecanismos de intencionalidade do sujeito, os da interação social e a maneira como as representações sociais se constituem". O autor conclui que certas noções são mais propícias à interdisciplinaridade que outras, justamente porque estão no centro destes diferentes mecanismos, e que tal é o caso da emoção.

O objetivo deste artigo é abordar a problemática da emoção por meio de uma situação de comunicação precisa, a saber, a troca verbal de informações face a face em contexto francófono. Nessa cena interativa, explora-se uma forma possível de identificação de emoção analisando índices linguísticos que por não ocuparem uma função sintática tradicional desempenham um papel discursivo perturbador, emotivo. Trata-se do redobramento do pronome pessoal da primeira pessoa em estruturas sintáticas deslocadas em geral e, em particular, em sequências comportando uma negação, a saber je ne sais pas moi (literalmente: eu não sei [,] eu).

A partir de análises dos dados linguísticos observados e repertoriados nessa cena definida (DE OLIVEIRA 2014, 2015): (i) associamos o enunciado je ne sais pas moi ao sentimento de aborrecimento do locutorinformante; (ii) mostramos de que maneira esse comportamento linguístico (global $\rightarrow$ particular) é incompatível com o contrato de cooperação 
(GRICE, 1975) que une os participantes em interações verbais; e (iii) postulamos sobre as consequências negativas desse comportamento nas relações entre os participantes da troca. As marcas linguísticas da presença do sujeito discursivo (ex.: formas pronominais, índices da primeira pessoa), possibilitam especular sobre a imagem que ele dá de si.

Este trabalho se estrutura em três partes.

$\mathrm{Na}$ primeira parte, aborda-se os aspectos fundamentais da problemática das emoções no discurso em geral, e foca-se nos aspectos pertinentes à esta proposta. A saber, evoca-se o papel das emoções na retórica discursiva argumentativa apoiando-se em trabalhos de Plantin (1999, 2011, 2013), dos quais adota-se a noção de enunciado emotivo (PLANTIN, 1999, p. 1). Por outro lado, ao considerar a emoção como uma parte da retórica concordamos com a proposta de Charaudeau (2010, p. 23) e abordamos os efeitos patêmicos do discurso segundo três características das emoções: i.e., elas são de ordem intencional, estão ligadas a saberes de crenças e se inscrevem numa representação psicossocial do sujeito.

Para dar conta do envolvimento emotivo do sujeito-discursivo a partir de realizações da forma pronominal índice da primeira pessoa (je-moi/eu), revisitamos a categoria gramatical do pronome sujeito nos referindo à teoria de Princípios e Parâmetros (CHOMSKY, 1957, 1981, 1995; CHOMSKY; LASNIK, 1993). Essa escolha teórica possibilita discutir o estado dos parâmetros do sujeito pleno em francês (ou seja, sua realização sistemática) e a partir daí estabelecer a correspondência entre o funcionamento sintático atual desses parâmetros e os efeitos pragmáticos-discursivos produzidos pelos pronomes pessoais. Para tanto, nos apoiamos, notadamente, no fenômeno da deslocação sintática comportando um redobramento pronominal em francês (LAMBRECHT, 1994; APOTHÉLOZ, 1997; BLASCO-DULBECCO, 1999).

$\mathrm{Na}$ segunda parte, apresentamos a metodologia de coleta dos dados, a saber, a observação participante (cf. BOGDAN; TAYLOR, 1975; LAPASSADE, 2002; SOULÉ, 2007). Na sequência, revisitamos o quadro referencial teórico da noção de interação verbal (SACKS; SCHEGLOFF; JEFFERSON, 2003 [1974]; KERBRAT-ORECCHIONI, 1994, 1996; MARCUSHI, 1999) e descrevemos a cena interacional na qual foram coletados os dados do corpus. Por a comunicação verbal estar relacionada com a falha ou sucesso das relações sociais, esta segunda parte comporta definições de conceitos e noções fundamentais à interpretação dos dados 
coletados, i.e., Contrato de Cooperação/Leis do discurso (cf. GRICE, 1975; DUCROT, 1979) e noções de face (cf. GOFFMAN, 1967; BROWN; LEVINSON, 1987).

$\mathrm{Na}$ terceira parte, analisa-se o corpus francês e propõem-se um esboço do perfil linguístico do locutor-informante do francês e seu impacto sociointerativo.

Por estudar como a linguagem acontece em um contexto real e definido, por buscar evidenciar como a linguagem nos constitui como pessoas em nosso contato com o outro, como a usamos para interagir em grupos sociais, que sentidos ela adquire nas mais diversas circunstâncias de interação, este artigo se insere na área de linguística aplicada e visa, assim, atuar na conscientização das pessoas sobre o poder e o impacto da linguagem nas práticas cotidianas.

\section{As emoções no discurso}

Enquanto as emoções ocupavam um lugar de destaque na retórica antiga, o campo de estudos da argumentação foi se autonomizando até estabelecer uma distinção entre, por um lado, o modelo de demonstração da lógica formal e, por outro, a persuasão (cf. POLO et al., 2013).

Séculos depois, logo que ocorreu uma refundação da argumentação como disciplina (cf. TOULMIN, 1958), as emoções ficaram ausentes desses trabalhos e mesmo o projeto de Perelman e Olbrechts-Tyteca (1958), o qual combina subjetividade e racionalidade, faz pouca menção ao papel das emoções na argumentação.

Mais tarde, nas teorias críticas da argumentação as emoções (re) aparecem, mas como índices do caráter falacioso ou potencialmente falacioso dos argumentos (cf. WALTON, 1992).

Já trabalhos recentes, particularmente aqueles que se apoiam em dados oriundos de situações autênticas, vêm mostrando a forte presença de emoções no discurso argumentativo e despertando assim o interesse por análises mais complexas do discurso emotivo-argumentativo (PLANTIN; DOURY; TRAVERSO, 2000; PLANTIN, 2011).

Nessas análises, o desafio não é julgar a validade dos argumentos, nem descrever o estado emocional real das pessoas, mas entender como os participantes de uma situação interativa mobilizam emoções em seu discurso com uma finalidade argumentativa. Tal é o objetivo deste trabalho. 
Considerando o leque vasto e complexo de manifestações das emoções no discurso, abordo a questão a partir da noção de enunciado emotivo.

O enunciado emotivo - do francês énoncé d'émotion - atribui uma emoção a uma pessoa e, em certos casos, menciona a fonte dessa emoção. Christian Plantin (1999) explica que esse tipo de enunciado é um modelo linguisticamente fundamental na medida em que ele designa à análise da palavra emocionada uma tarefa fundamental que consiste, primordialmente, em determinar quem sente o quê, e eventualmente por quê. No que diz respeito à determinação de o quê, a lista de termos de emoção é extensa, e inclui provavelmente centenas de termos básicos como medo, cólera, indignação, vergonha..., mas não é exclusiva. De fato, a investigação da dimensão emotiva do discurso também inclui enunciados como "Eu estou fervendo", 1 que embora não comportando nenhum termo de emoção, indica que "Eu", o experimentador, estou realmente sentindo alguma coisa e que, certamente, não é vergonha, medo ou alegria mas talvez algo como indignação, talvez impaciência. Portanto, "Eu estou fervendo" é um enunciado emotivo.

Como toda enunciação supõe um locutor e um ouvinte e, no primeiro, a intenção de influenciar, de algum modo, o outro (BENVENISTE, 1974), todo discurso busca também exercer de uma maneira ou de outra alguma influência, orientando modos de ver, de agir, de pensar, de sentir (ANSCOMBRE; DUCROT, 1997). Assim, o enunciado "Eu estou fervendo" desempenha duas funções discursivas: a emotiva e a argumentativa. Em outras palavras, o locutor eu endereça ao interlocutor um argumento, estou fervendo, e espera que, a partir daí, o interlocutor adote os comportamentos adequados.

Nosso propósito é mostrar que o enunciado je ne sais pas moi também possui essa função emotiva argumentativa. E que isso acontece quando "les conditions de cohérence et de véridicité ne suffisent pas en effet pour assurer qu'un discours 'perce', si l'interlocuteur n'est nullement touché, la véridicité et la cohérence font peu de sens en lui et la communication ne le change

\footnotetext{
${ }^{1}$ Em Arguing emotions, para ilustrar seu posicionamento, Plantin (1999, p. 8) propõe a sequência "Peter was boling".
} 
pas."2 (CIGADA, 2008, p. 145). Ao enunciar je ne sais pas moi o locutor diz/ argumenta "eu já respondi que não sei mas parece que você não entendeu ou não quer entender, ou que duvida de mim”, e mostra assim uma emoção, seu sentimento de aborrecimento.

Para avaliar essa hipótese, como anunciado, levamos em conta três caraterísticas da problemática discursiva das emoções, segundo Charaudeau (2010, p. 26). A saber: (i) as emoções são de ordem intencional; (ii) estão ligadas a crenças; e (iii) se inscrevem na representação psicossocial.

Em primeiro lugar, a emoção não é redutível a uma sensação nem a uma pulsão irracional, ela é de ordem intencional. Vista desse modo, como observa Elster (1995), a racionalidade está ao serviço de um agir para alcançar um objetivo (não necessariamente atingido) cujo agente seria, de uma maneira ou de outra, o primeiro beneficiário: ela compreende, assim, uma "visada acional". Charaudeau sugere que essa visada, "concebida finalmente como busca de um objeto” (CHARAUDEAU, 2010, p. 28), deve ser desencadeada por algo e esse algo é da ordem do desejo, visto que, no final das contas, o agente se vê como beneficiário. Por isso, a racionalidade deve ser qualificada como "subjetiva" pois aparece como o resultado de uma escolha entre um conjunto (de escolhas possíveis), o que também leva a supor que o locutor possui conhecimentos sobre suas vantagens e inconvenientes. Como esses conhecimentos, por sua vez, são "relativos ao sujeito, às informações que ele recebeu, às experiências que ele viveu e aos valores que ele lhes atribuiu, podemos dizer que a racionalidade está ligada às crenças" (CHARAUDEAU, 2010, p. 28).

A noção de "crenças" constitui a segunda característica da problemática discursiva das emoções. Neste estudo, veremos que por elas serem: (i) constituídas por um saber polarizado em torno de valores socialmente compartilhados; (ii) o sujeito mobiliza uma, ou várias, das redes inferenciais propostas pelos universos de crenças disponíveis na situação onde ele se encontra, o que é susceptível de desencadear nele um estado emocional; e (iii) o desencadeamento do estado emocional (ou sua ausência) o coloca em contato com uma sanção social que culminará em julgamentos diversos de ordem psicológica ou moral (CHARAUDEAU, 2010, p. 30).

\footnotetext{
2 "as condições de coerência e veracidade não são suficientes para assegurar que um discurso" "irrompe", se o interlocutor não é afetado de forma alguma, a verdade e a coerência fazem pouco sentido nele e a comunicação não o muda". Tradução literal nossa.
} 
Por fim, levaremos em conta que as emoções se inscrevem em uma problemática da representação psicossocial e que essa representação pode ser, segundo Charaudeau (1995, p. 31), "patêmica"3 e/ou sociodiscursiva. Ela é patêmica quando descreve uma situação a propósito da qual um julgamento de valor coletivamente compartilhado - e por conseguinte, instituído em norma social - questiona um actante que acredita ser beneficiário ou vítima, e ao qual o sujeito da representação se encontra ligado de uma maneira ou de outra. Quanto à qualificação de sociodiscursiva, esta é reservada para as representações que implicam o sujeito, os engajam em uma tomada de posição no que diz respeito aos valores, em oposição aos saberes de conhecimento que lhe são exteriores, não lhe pertencem, vêm até ele e não o implicam. Em suma, as representações sociodiscursivas são "como mini narrativas que descrevem seres e cenas da vida, fragmentos narrados [...] do mundo que revelam sempre o ponto de vista de um sujeito." (CHARAUDEAU, 2010, p. 32).

Essas três caraterísticas da problemática das emoções no discurso serão avaliadas segundo os seguintes critérios: (i) na cena interativa onde foram repertoriados os elementos do tratamento discursivo, ou seja, em trocas verbais de informação face a face; (ii) segundo um dos campos temáticos da emoção, i.e., o sentimento de aborrecimento; e (iii) a partir dos traços linguísticos que caracterizam esta emoção, a saber, estruturas sintáticas comportando um redobramento pronominal, índice da primeira pessoa.

\subsection{O sujeito verbal pronominal em francês: princípios e parâmetros}

Para tratar do problema da realização do sujeito verbal pronominal em francês e, a partir daí, especular sobre o posicionamento discursivo do sujeito-locutor, referindo-se a princípios teóricos oriundos da Gramatica Gerativa, notadamente à teoria dos Princípios e Paramêtros (PP).

A partir dos trabalhos de N. Chomsky (1957, 1981, 1995; CHOMSKY; LASNIK, 1993), estabeleceu-se a notória divisão das línguas do mundo em dois grupos: o de sujeito nulo, comportando as línguas que permitem a

\footnotetext{
${ }^{3} \mathrm{O}$ autor utiliza os termos "pathos", "patêmico" e "patemização" em lugar de emoção, por dois motivos: essa escolha permite inserir a análise das emoções na filiação da retórica que desde Aristóteles trata os discursos em uma perspectiva de visada e efeitos. Por outro lado, tal escolha possibilita dissociar a análise do discurso, caso seja necessário, da psicologia e da sociologia (CHARAUDEAU, 2010, p 35).
} 
não-realização do sujeito (ex.: línguas românicas) e o de sujeito pleno, que reagrupa as línguas que exigem o sujeito realizado (ex.: línguas germânicas). A explicação inicialmente proposta para esse fenômeno, também chamado de parâmetro pro-drop, é que certas línguas apresentam uma morfologia verbal rica (cf. a língua italiana), enquanto que em outras o paradigma flexional é limitado (cf. a língua inglesa). Esse argumento vem sendo revisto e ampliado em inúmeras pesquisas. ${ }^{4}$ De fato, é possível assim constatar que o grupo de línguas de sujeito nulo comporta pelo menos três categorias: as línguas de sujeito nulo consistente, como o português europeu, o italiano e o espanhol; as de sujeito nulo parcial, como o português brasileiro e o finlandês (HOLMBERG, 2005) e as línguas de pro-drop radical, como o japonês e o chinês (HUANG, 1984).

No que diz respeito ao grupo de línguas de sujeito pleno, reagrupamse aí tanto o inglês, uma língua de morfologia verbal flexional limitada, como o francês, uma língua cujo paradigma verbal morfológico é variado, mas de fraca realização fonética.

Em suma, as caraterísticas pronominais sublinhadas apontam para mudanças na marcação dos parâmetros do sujeito: em PB, uma língua de sujeito nulo mas nulo parcial, e como em francês, devido a seu paradigma verbal variado, mas de fraca realização fonética. Estudos vêm evidenciando uma estreita relação entre essas mudanças e as chamadas "construções de tópico".

Para mostrar essa relação, adotamos o postulado de Benveniste segundo o qual

[e]nquanto realização individual, a enunciação pode se definir, em relação a língua, como um processo de apropriação. O locutor se apropria do aparelho formal da língua e enuncia sua posição de locutor por meio de índices específicos [cf. Pronome Pessoal Sujeito - PPS], de um lado, e por meio de procedimentos acessórios [cf. deslocação pronominal, tópico pronominal marcado], de outro. (BENVENISTE, 1989, p. 84)

\footnotetext{
${ }^{4}$ J. Huang (1984) mostra, por exemplo, que línguas como o chinês e o japonês, cujos verbos não apresentam nenhuma marca número-pessoal, também possuem sujeitos nulos. Holmberg (2005) evidencia aspectos do sujeito nulo parcial em finlandês. Em "Null subjects: a reanalysis of the data", Yan Huang (2000) apresenta uma visão abrangente da problemática do sujeito nulo.
} 
$\mathrm{Na}$ sequência, descrevo as condições sintáticas e os efeitos pragmáticos-discursivos relacionados à realização do sujeito pronominal (je/eu) em francês.

\subsection{O francês, língua de sujeito pleno}

Consideremos:

(1a) Je sais nager. [Eu] sei nadar.

Do ponto de vista sintático, no que diz respeito à realização do PPS em francês, seu emprego é sistemático (*sais nager), porque nessa língua não se constroem frases com sujeito desinencial. Com efeito, em francês moderno, salvo exceções (ex.: uso de formas verbais imperativas e nominais) "nenhuma forma verbal pode ser empregada sem pronome" (BENVENISTE, 1989, p. 203). Portanto, o francês é uma língua de sujeito pleno, ou seja, uma língua na qual os falantes necessitam obrigatoriamente preencher todos os PPS, independentemente das condições em que aparecem ou do tipo de verbo que acompanham. Tal necessidade de preenchimento ocorre em francês devido ao seu paradigma flexional pouco diversificado foneticamente, o que impede a identificação do sujeito através das desinências verbais. De fato, enquanto os verbos do segundo e do terceiro grupos apresentam cinco variações morfológicas (e quatro distinções fonéticas), os verbos do primeiro grupo possuem cinco variações morfológicas e apenas três distinções fonéticas.

De origem nominal e ligados a uma categoria que se aparenta a do nome, os PPS só vão adquirir um estatuto de palavra funcional a partir do século XV (cf. DUFRESNE, 1995). Desse período da língua medieval decorrem ainda duas outras mudanças no comportamento desses elementos: a mudança acentual, que consiste na transferência de acento da palavra para o acento do sintagma, e da aparição de uma série de pronomes tônicos (moi, toi, lui/elle, nous, vous, ils/elles) ao lado da série dos átonos, já existente (je, tu, il/ elle, nous, vous, ils/ elles).

Em sua evolução, os PPS do francês vão assim se repartir em duas grandes categorias: a dos pronomes clíticos (também chamados de "átonos") e a dos tônicos. Enquanto os clíticos permanecem sintaticamente ligados ao verbo formando uma unidade fônica, os tônicos são formas relativamente autônomas que, por beneficiarem uma grande mobilidade, assumem diversas funções tanto sintáticas quanto pragmático discursivas. A análise gramatical 
de uma das realizações do fenômeno da deslocação sintática, a saber, o redobramento da forma pronominal átona pela forma tônica, tanto na posição inicial à esquerda do verbo quanto à direita, na posição final absoluta ou não, permite evidenciar a presença do locutor, seu posicionamento pragmático discursivo, assim como seu envolvimento emotivo.

\subsection{Efeitos emotivos da deslocação pronominal}

Emprego a denominação "deslocação sintática" no sentido descrito por Lambrecht (1994, p. 1050):

The dislocation construction (also called detachment construction) is a sentence structure in which a referential constituent which could function as an argument or an adjunct within a predicate-argument structure occurs instead outside the boundaries of the clause containing the predicate, either to its left (left-dislocation [...]) or to its right (rightdislocation $[\ldots]) .^{5}$

Do ponto de vista semântico-pragmático, os dois tipos de deslocação apontados por Lambrecht se distinguem basicamente da seguinte maneira:

The left dislocation construction is often used to mark a shift in attention from one to another of two or more already active topic referent. This explains the frequent occurrence of PRONOMINAL NPs in detached position (Me, I'm hungry, Moi, j'ai faim). Such detached lexical or pronominal NPs often have a "contrastive" function, in which case they may be referred to as CONTRASTIVE topic NPs [...]. (LAMBRECHT 1994, p. 1050) ${ }^{6}$

\footnotetext{
5 "A construção de deslocamento (também chamada de construção de tópico) é uma estrutura na qual um constituinte referencial que poderia funcionar como um argumento ou como um adjunto dentro de uma estrutura com argumento-predicado ocorre fora dos limites da cláusula que contém o predicado, seja à sua esquerda (deslocação à esquerda) [...]) seja à sua direita (deslocação à direita [...])." 'Tradução literal nossa.

${ }^{6}$ A construção de deslocamento à esquerda é frequentemente usada para marcar uma mudança de atenção de um para outro de dois ou mais referentes tópicos já ativos. Isso explica a ocorrência frequente de NPs PRONOMINAIS em posição destacada (Me, I am hungry; Moi, j'ai faim). Esses PNs lexicais ou pronominais destacados geralmente têm uma função "contrastiva", e nesse caso eles podem ser referidos como NPs de tópico CONTRASTIVO [...]. (LAMBRECHT 1994, p. 1050).” (CECCHETTO, 1999, p. 40). Tradução literal nossa.
} 
No meio de debates e controvérsias sobre a deslocação à esquerda (DE) observa-se um consenso no que diz respeito à sua função pragmática de marcação do tópico: termo aqui entendido como parte de uma caracterização binária da estrutura sintática cujo oposto é o comentário (retomando o exemplo acima: Moi tópico $\rightarrow$ j'ai faim comentário). Como se pode observar no extrato abaixo, a dupla realização do PPS desempenha um papel determinante na gestão da interpretação do discurso:

A se endereça a B num ponto de ônibus.

A: Vous avez l'heure? Você tem horas?

B: Désolé, je n'ai pas de montre. Sinto muito, não tenho relógio.

C: Moi j'en ai une. Eu, eu tenho um.

No contexto acima, ao se topicalizar, o sujeito-falante (C) não somente estabelece uma relação de contraste ( $\mathrm{B}$ vs $\mathrm{C}$ ) mas se torna a vedete da interação (i.e., "ele não tem relógio mas eu tenho um").

No que diz respeito à deslocação à direita (DD), pesquisas revelam que contrariamente à DE, a DD não possui etiquetas. Como mostra Cecchetto (1999),

The pragmatics features of [DD] and [DE] are similar, though not identical: roughly speaking, the right dislocated element in DD is associated with familiar information, as it is the left dislocated element in [DE]. While the literature on [DE] is quite large [...], the discussion on [DD] is more limited (incidentally, this is also shown by the fact that no well-established label exists for the right dislocation construction). (CECCHETTO, 1999, p. 40) ${ }^{7}$

O consenso acerca da DD é que essas construções - contrariamente à DE - não desempenham o papel de contraste (LAMBRECHT, 1994, p. 183). Em sua abordagem diacrônica e tipológica desse fenômeno em algumas línguas romanas, R. Simone (1997, p. 48) mostra que

\footnotetext{
7 “As características pragmáticas da [DD] e da [DE] são semelhantes, embora não idênticas: grosso modo, o elemento deslocado à direita em DD está associado a informações familiares, assim como é o elemento deslocado à esquerda em [DE]. Enquanto a literatura sobre [DE] é bastante vasta [...], a discussão sobre [DD] é mais limitada (aliás, isso também é demonstrado pelo fato de que não existe um rótulo bem estabelecido para a construção com deslocamento à direita). (CECCHETTO, 1999, p. 40). Tradução literal nossa.
} 
[D]'un côté, la classe des dislocations (DD et dislocations à gauche, DG) est une innovation romane généralisée: on en trouve beaucoup en roumain, français, italien, espagnol, pour ne pas parler des dialectes de ces langues. Cependant, ces structures ont, de langue à langue, une distribution non homogène et des destins diachroniques distincts. En particulier, si la DG demeure active comme forme de mise en relief, la DD perd cette propriété au moment où elle devient une structure non marquée, de type general purpose, à côté de SVO. ${ }^{8}$

Como Nølke (1997) pensamos que a função principal da DD é mostrar o envolvimento emocional do falante. As dificuldades inerentes à análise dos efeitos produzidos por esse tipo de deslocação devem-se à complexidade de uma conceituação de emoções subjacentes à expressão linguística. Todavia, em certos contextos precisos, é possível associar as DD a tipos de emoção.

Em suma,

(i) A duplicação pronominal na DE suj-locutor é um fenômeno repertoriado em francês, onde esse jogo pronominal - de formas diversificadas ou únicas - permite produzir um efeito de contraste entre o locutor e um ou mais interlocutores e/ou de posicionar o locutor em vedete do discurso.

(2a) Moi, je sais nager. Eu, eu sei nadar.

Por se distinguir da ordem canônica SVO, a DE suj-locutor (2a) deve ser vista como uma estratégia emotiva suscetível de indicar o contentamento do locutor.

(ii) No que diz respeito à DD suj-locutor, postulamos que essa construção indica seu sentimento de aborrecimento em respostas comportando uma negação. Nesse caso, do ponto de vista da pronúncia a sequência francesa não comporta nenhuma pausa.

(3a) Je ne sais pas nager moi.

\footnotetext{
8 “Por um lado, a classe das deslocações (DD e deslocação à esquerda, DE) é uma inovação românica generalizada: encontramos muitas em romeno, francês, italiano, espanhol, para não mencionar os dialetos dessas línguas. No entanto, essas estruturas têm, de uma língua à outra, uma distribuição não homogênea e destinos diacrônicos distintos. Em particular, se a DE permanecer ativa como uma forma de ênfase, a DD perde essa propriedade à medida que ela se torna uma estrutura de propósito geral não marcada ao lado da sequencia SVO." Tradução literal nossa.
} 
Partindo dessas considerações fundamentais, exploramos as hipóteses acima na quarta parte deste trabalho.

$\mathrm{Na}$ sequência é descrito o quadro teórico metodológico, a cena interacional, e apresenta-se as definições das noções de cooperação, face e polidez linguística.

\section{Arcabouço teórico metodológico}

\subsection{O método observação participante}

O método de observação e coleta dos dados analisados neste estudo é de cunho etnográfico e se inspira na observação participante (cf. BOGDAN; TAYLOR, 1975; LAPASSADE, 2002; SOULÉ, 2007), uma técnica de pesquisa de cunho etnográfico que consiste na imersão ativa do pesquisador na comunidade - (ou grupo) foco da pesquisa. Este método, usado para coletar dados de várias fontes, tanto permite obter informações complementares àquelas já coletadas, como melhor entender certos aspectos do funcionamento das relações (aqui, sociodiscursivas) entre os membros da dita comunidade (ou grupo). Oriunda da observação participante, a noção de entrismo (cf. LAPASSADE, 2002) significa que o pesquisador entra em um ambiente sem indicar a verdadeira finalidade da sua adesão, ou seja, o pesquisador pode conduzir a pesquisa de forma declarada (pesquisador declarado - ouvert researcher) ou escondida (pesquisador escondido couvert researcher). Considerando o cunho desta pesquisa (cf. identificação do comportamento linguístico emotivo de participantes na troca de informações), afim de assegurar a autenticidade das produções verbais nas interações observadas, a coleta foi feita de forma escondida. Essa escolha inclui: (i) a observação participante em si (o pesquisador observa os pesquisados e pode vir a compartilhar suas atividades); e (ii) entrevistas sob forma de conversas casuais/informais (em que os pesquisados revelam, por exemplo, seu ponto de vista sobre aspectos de sua vida sócio profissional ou aspectos de si mesmos).

Os detalhes da coleta se encontram abaixo. A análise dos dados coletados se encontra na quarta parte. 


\subsection{Aspectos básicos da interação verbal}

Por ser de vocação comunicativa, o exercício da fala implica uma alocução, uma interlocução e uma interação (cf. KERBRAT-ORECCHIONI, 2006 [1999]). Em outras palavras, a troca comunicativa verbal é sempre resultante de uma atividade interpessoal desenvolvida entre pelo menos dois indivíduos através de um determinado canal (real ou virtual). De fato, "a presença física não caracteriza a interação conversacional em si, mas sim determinados gêneros, tais como os que se dão nos encontros face a face." (MARCUSHI, 2002, p. 14-15).

A interação face a face, como troca comunicativa verbal, se realiza das mais diversas maneiras, sendo algumas delas as conversas de todos os tipos (entre amigos, familiares, conhecidos, desconhecidos), as consultas de todos os tipos (profissionais, por exemplo, médicas), as entrevistas, os debates, as transações comerciais, as trocas didáticas, os encontros científicos, as reuniões de trabalho, as sessões de tribunal, as conferências diplomáticas... (cf. KERBRAT-ORECCHIONI, 2006 [1999]). Resulta que cada uma delas se caracteriza individualmente pelos entornos espaço-temporal e sóciohistórico que unem os participantes.

Os temas abordados numa situação face a face são abrangentes e podem ser predefinidos ou não. A esse propósito, é essencial lembrar que as trocas comunicativas reais não são obrigatoriamente tipologicamente fixas. Com efeito, numa conversa de tema não predefinido - na qual se fala de tudo e de nada - é possível e comum passarmos de um tema banal (ex.: troca de comentários sobre o aumento do preço da passagem de ônibus) a questões mais elaboradas (ex.: troca de ideais sobre estratégias de manifestações contra o aumento da passagem de ônibus) e vice-versa. Também vale ressaltar que uma interação verbal predefinida (ex.: debate sobre a legitimidade de manifestações estudantis) pode bifurcar para outros temas (ex.: o papel da polícia na sociedade). Em todos esses contextos só é todavia possível falar de interação se houver participação e engajamento de ambas as partes. Essa mobilização mútua se manifesta por diversos procedimentos - linguísticos e/ou comportamentais - de validação interlocutória.

Portanto, a interação face a face pode e deve ser considerada como o produto de um trabalho colaborativo incessante envolvendo classes sociais, grupos étnicos, relações de poder, entre outros. Trata-se, em suma, da experiência linguística por excelência (cf. MARCUSHI, 1999, 2008, 2010). 
A análise de mecanismos interacionais (cf. SACKS; SCHEGLOFF; JEFFERSON, 2003 [1974]) vem servindo de aparato metodológico através do qual é possível ver como "nos eventos de fala-em-interação as pessoas se organizam de forma a constituir [suas] identidades (e relações [em geral]) de maneira que elas sejam relevantes socialmente em contextos situados" (SILVA; ANDRADE; OSTERMANN, 2009, p. 2-3). Quanto a outros aspectos da interação verbal, relevando particularmente conhecimentos linguísticos, paralinguísticos e socioculturais (cf. GUMPERZ, 1982), sua investigação permite repertoriar elementos que são ou devem ser compartilhados para que a troca seja bem (ou mal) sucedida.

É nesta ótica que se situa esta pesquisa: proponho ultrapassar a análise das estruturas propriamente ditas e atingir o processo cooperativo (cf. GRICE, 1982 [1967]) presente na atividade conversacional, passando assim da problemática da organização para a da interpretação. (MARCUSHI, 2002)

Para tanto, o ponto de partida é a especificação dos critérios básicos que possibilitaram precisar onde, quem, o quê, como do tipo de atividade verbal, servindo de cena interacional a este estudo, a saber, a troca de informações.

\subsubsection{A troca de informações face a face}

A troca de informações consiste em uma forma de conversação de cunho transacional entre duas pessoas que não se conhecem. Sua natureza dialógica é fundamentada no par pergunta-resposta. Este par é moldado por códigos linguísticos e sociais normativos. O eventual rompimento de qualquer um desses códigos altera o funcionamento da troca levando os participantes a buscarem estratégias discursivas outras que aquelas previstas no script, e acarretando assim uma série de implicações - negativas ou positivas - na relação entre os participantes.

Para aprofundar essas questões, está descrito e associado no corpus dados referentes aos fatores variáveis do processo interacional (a saber, perfil dos participantes, momento da história, códigos e lugares sociais), a princípios do fator constante apontado por Grice (1982 [1967]), ou seja, aqueles atinentes ao Contrato de Cooperação e às suas máximas. 


\subsubsection{Fatores variáveis}

Os fatores variáveis de interações envolvendo a troca de informações foram observados através de quatro critérios de investigação (cf. KERBRATORECCHIONI, 2006, p. 13 [1999]), a saber,

\section{i) A natureza do lugar (quadro espaço-temporal)}

As situações interacionais de troca de informação face a face analisadas neste estudo foram observadas na França metropolitana, em Nice e Paris entre 2009 e 2017, em lugares públicos e privados (i.e., instituições governamentais, escritórios, bilheterias, balcões/quiosques), em ambientes abertos ou fechados.

\section{ii) O número de participantes, seus estatutos e papéis, e o tipo de con- trato que os une}

Os extratos coletados e analisados neste trabalho (seis situações) consistem em diálogos entre duas pessoas - adultas, de ambos os sexos cuja faixa etária pode ser calculada a partir de 18 anos - que não se conhecem. Uma delas solicita uma informação (i.e., um solicitante, de estatuto social indeterminado), enquanto que a outra fornece a informação, sua função é definida (i.e., um informante, de estatuto social determinado, ou seja um funcionário público ou empregado de uma empresa).

Os papéis interativos dos participantes da troca são móveis; enquanto seus papéis interacionais (aquele que pergunta vs aquele que responde) se caracterizam por sua relativa estabilidade. Como em qualquer troca verbal, esses locutores estão ligados por um contrato de cooperação. Este se alicerça em quatro categorias sob uma ou outra das quais cai(em) certas máximas e submáximas mais específicas que produz(em), em geral, resultados em acordo com o Princípio de Cooperação: São as notórias categorias de: Quantidade (a informação dada é suficiente), Qualidade (a informação é verídica), Relação (a informação é pertinente) e Modo (a informação é clara e concisa). (GRICE, 1982 [1967]).

Como observam Reboul e Moeschler (1998, p. 51), o interesse principal das máximas de Grice não é tanto o fato de que elas devem ser respeitadas; o que há de inovador é que essas máximas possam ser exploradas pelos interlocutores. 


\section{iii) O objetivo da interação e a relação entre participantes}

Importa ressaltar que o que se denomina comumente "troca de informações" consiste na maior parte do tempo em uma situação face a face na qual um locutor faz uma pergunta a um destinatário que lhe responde. Todavia, nesse mesmo contexto, também pode acontecer uma "troca" no sentido literal do termo. Isso se observa quando a pergunta não ficou clara para o destinatário, ou ainda quando a resposta requer um complemento de informação relativo à pergunta formulada (ex.: no balcão de uma companhia ferroviária o solicitante pergunta se há lugares disponíveis num determinado trem e o informante pergunta em que classe o solicitante deseja viajar; na bilheteria de um museu o solicitante pergunta se crianças pagam entrada e o informante pergunta a idade das crianças). Em todos os casos, os participantes devem se submeter ao respeito das máximas conversacionais a fim de atingir o objetivo da interação que consiste na eficácia máxima da troca de informações. A relação entre estes interlocutores é essencialmente transacional.

\section{iv) Grau de formalidade e estilo}

Por tratar-se de uma relação transacional entre pessoas que não se conhecem, do ponto de vista linguístico observou-se, em primeiro lugar, o estilo formal do informante. Essa característica linguística da troca é particularmente notável no que toca ao uso de fórmulas de abertura, como bonjour/bonsoir (bom dia/boa tarde/boa noite); como de fechamento, au revoir, seguidas de madame (senhora), monsieur (senhor) ou variantes.

Como mencionado, os papéis interativos (locutor vs interlocutor) são móveis. Portanto, o solicitante pode vir a adotar não só o mesmo estilo como também o mesmo nível de linguagem do informante. Assim, geralmente, ambas as partes fazem um uso formal da língua, cujas manifestações básicas (ex.: substituição de formas verbais no presente do indicativo pelo modo condicional) se articulam a partir do uso sistemático do pronome vous (vós, singular/plural). Se, por um lado, se exclui o uso da linguagem coloquial (emprego de gírias, relaxamento abusivo de regras gramaticais, entre outros), por outro, não é necessário o uso da língua culta que, por representar a norma, pode vir a prejudicar as relações entre os participantes (sobretudo quando um deles a ignora, pelas mais diversas razões, sendo uma delas a falta de instrução formal). 
No que diz respeito aos papéis interacionais (aquele que pergunta vs aquele que responde), embora caraterizados por sua relativa estabilidade, o fato do informante, "aquele que responde", possuir um estatuto social definido (ex.: funcionário ou empregado, formado/preparado/treinado para a função que ocupa), seu papel é/deve ser ainda mais estável que o daquele que pergunta, o qual, como vemos, não corresponde em princípio a nenhum estatuto particular (ex.: cliente/turista, entre outros). A título de ilustração, consideremos que A tenta obter uma informação ou informações junto a B. A não tem certeza se B tem essa informação, mas arrisca a pergunta. B possui o script da troca, portanto, sua resposta é "sim" ou "não". Todavia, é importante lembrar que a relação entre o contexto e o texto conversacional não é unilateral, mas dialética. Com efeito, face, por exemplo, a uma resposta negativa de B, A insiste/reformula a pergunta, o que leva B a sair do script e adotar novas estratégias discursivas. Assim, embora definida de início, "a situação é incessantemente redefinida pelo conjunto de acontecimentos conversacionais". Isso ocorre porque o "discurso é uma atividade, ao mesmo tempo, condicionada (pelo contexto) e transformadora (desse mesmo contexto)". (KERBRAT-ORECCHIONI, 2006, p. 35).

\subsubsection{Fator constante}

O fator constante da troca verbal, ou seja, o Contrato de Cooperação, é "um princípio muito geral que se esperaria (ceterisparibus) que os participantes observassem: Faça sua contribuição conversacional tal como é requerida, no momento em que ocorre, pelo propósito ou direção do intercâmbio conversacional em que você está engajado." (GRICE, 1982, p. 4).

Do ponto de vista teórico metodológico, recorrendo a Ducrot (1987, p. 96), constatamos que "o recurso às leis [do discurso em análises do intercâmbio verbal] permite manter o valor explicativo da significação sem a sobrecarrega de todas as nuances localizáveis na observação dos enunciados". Em outras palavras, o recurso às leis do discurso permite resolver certos problemas ligados à subdeterminação de enunciados. Para ilustrar este posicionamento, consideremos a situação abaixo na qual A (uma locutora/cliente) se endereça a B (informante/vendedora) numa loja de prêt-à-porter. 
A: Bonjour. Est-ce que vous avez ce modèle en noir? Bom dia. Você tem esse modelo na cor preta?

B: Tout est là madame. Está tudo aí senhora.

Recorrendo às máximas, a situação acima pode ser interpretada da seguinte maneira: a informação dada por B é suficiente (todos os produtos estão expostos, portanto se um produto de cor preta não se encontra entre eles é porque esse produto não existe na cor desejada ou está esgotado), de acordo com a máxima de quantidade; essa informação é verídica (parte-se do princípio que $\mathrm{B}$ conhece seu trabalho, o qual consiste essencialmente em vender; logo, B tem todo interesse em dizer a verdade a cada vez que esta acarreta benefícios para seu empregador e/ou para ela mesma), de acordo com a máxima de qualidade; essa informação é pertinente (todos os produtos disponíveis se encontram expostos na loja), de acordo com a máxima de relação; por fim, a informação dada é clara e concisa (todos os produtos da loja estão expostos, o que inclui os produtos de todas as cores), de acordo com a máxima de modo. Em suma, nesta situação observa-se a aplicação do Contrato de Cooperação.

Por outro lado, ao levarmos em conta a natureza e as condições que governam a conversação, o que inclui a troca de informações acima, podemos também formular hipóteses e conclusões suplementares, ou seja, podemos calcular "implicaturas conversacionais". Grice explica que calcular uma implicatura conversacional é calcular o que deve ser suposto a fim de preservar a suposição de que o Princípio de Cooperação está sendo observado. E já que pode haver várias explanações específicas possíveis, formando às vezes uma lista aberta, o implicitado conversacional em tais casos será a disjunção de tais explanações; e se a lista é aberta, o implicitado terá exatamente o tipo de indeterminação que muitos implicitados efetivos parecem ter. (GRICE, 1982, p. 13-14 [1967]).

Portanto, a sequência “tout est là/está tudo aî" pode vir a ser interpretada de diversas outras maneiras. Ao constatarmos, por exemplo, que $\mathrm{B}$ responde à pergunta sem efetuar uma verificação, formulamos as seguintes hipóteses: como garantir que todos os produtos se encontram realmente expostos? Talvez o produto solicitado se encontre entre outros produtos ou no estoque da loja, ou numa outra loja (matriz ou filial); talvez seja possível encomendar o produto; ou talvez esse produto nunca tenha existido na cor solicitada. Desse modo, concordamos com Ducrot, segundo 
o qual hipóteses e/ou conclusões suplementares estão relacionadas a dois tipos de "implícitos", a saber, os "pressupostos" que estão "necessariamente inscritos na significação das frases, e os "subentendidos", considerados "como um produto das leis do discurso" (DUCROT, 1987, p. 98 [1984]). A propósito de "subentendidos", eles podem ser entendidos como: (i) insinuações escondidas por traz de uma afirmação; (ii) o subentendido é de responsabilidade do ouvinte, já que o falante se esconde por trás do sentindo literal das palavras e pode dizer que não estava querendo dizer o que o ouvinte compreendeu; e (iii) o subentendido serve para o falante proteger-se diante de uma informação que quer transmitir para o ouvinte sem se comprometer com ela. Desse modo, poder-se-ia pressupor que "tout est là/está tudo aí" subentende que "B não se importa com A", já que tal sequência permite o fechamento da troca onde B indica ter feito sua parte e da qual ela se retira, por já ter dito tudo que tinha para dizer.

O que acaba de ser posto mostra que ao relacionarmos critérios especificados às máximas conversacionais/leis do discurso obtemos um aparato teórico metodológico interpretativo que tanto permite observar o funcionamento ordinário da troca verbal e clarificar questões envolvendo enunciados subdeterminados quanto especular sobre o que acontece quando há violação do contrato de cooperação.

Levando em conta que a comunicação verbal é relação social e que as relações sociais estão intimamente relacionadas à noção de face, é legítimo submeter o bom funcionamento da comunicação às regras de polidez.

\section{$4 \mathrm{Im} /$ polidez linguística e suas relações com a face}

Dos tempos da retórica clássica (ARISTÓTELES, 2005), passando pelos diálogos do Renascimento italiano (WAUTHION; SIMON, 2000) a noção de polidez atravessou o século XIX romântico (ROUVILLOIS, 2006) e chega aos dias de hoje como um componente social do discurso, um ritual, uma norma e uma competência social valorizada e valorizante. No contexto da abordagem interacional contemporânea, entendida numa perspectiva dialógica, a polidez linguística adquiriu um status de objeto científico relevante e verifica-se que se tornou um componente de honra na análise do discurso. 
Porque cada período da história tem suas normas de polidez, e que tais normas possuem suas especificidades em cada comunidade, o estudo das interações verbais

ne peut faire abstraction de ce qui est perçu comme poli/impoli socialement. Il s'agit, pour l'analyste, de s'intéresser aux stratégies discursives qui sont utilisées par les différents participants à une interaction à la lumière des codes sociaux en vigueur au moment où ces échanges ont lieu. (JOBERT, 2010, p. 8) ${ }^{9}$

No que diz respeito ao funcionamento de trocas verbais e suas implicações sociais, na extensão de seus trabalhos pioneiros sobre questões de polidez, Lakoff (1989) mostrou, por exemplo, que se o desacordo e o conflito são elementos inerentes, sistemáticos e normais num debate, estes mesmos elementos representam uma ameaça ao bom funcionamento das trocas corriqueiras, onde, portanto, devem ser evitados. Desde então, objetivando um melhor conhecimento dos processos que conduzem ao sucesso ou à falha das interações, as teorias e as descrições da polidez linguística abrangem variedades de troca que vão muito além da conversação ordinária.

Ao considerarmos a troca de informações como uma forma de conversação, torna-se legítimo vê-la como um lugar onde o eu deve traçar e preservar os limites do seu território. No palco da conversação, o sujeito social, animado por um desejo de face (GOFFMAN, 1967), aciona diferentes estratégias para proteger a sua face ou negociar/manipular a face de seu interlocutor.

Portanto, a troca de informações, como qualquer outra forma de conversação, é atravessada por atos ameaçadores da fala (face threatening acts ou FTA) (BROWN; LEVINSON, 1987) ou temperada por atos lisonjeiros da fala (face flattering acts ou FFA) (KERBRAT-ORECCHIONI, 2010). Neste jogo interacional, a polidez [linguística] é o recurso que sela o pacto latente entre os participantes (GOFFMAN, 1967, 1973, 1987): não ameaço sua face se você não puser a minha em perigo. Sabe-se, todavia,

\footnotetext{
9 "Não pode ignorar o que é percebido como polido ou socialmente impolido. Cabe ao analista interessar-se pelas estratégias discursivas utilizadas pelos diferentes participantes em uma interação à luz dos códigos sociais vigentes no momento em que essas trocas ocorrem. "(JOBERT, 2010, p.: 8) Tradução literal nossa.
} 
que as ameaças são constantes e se manifestam através dos mais diversos comportamentos linguísticos - entre outros, interrupções, discordâncias, procedimentos irônicos, respostas negativas - os quais podem ofender, agredir, desprezar, provocar o adversário e transformar a conversação numa luta emocional. Por fim, vale lembrar que nem sempre os participantes dessa luta emocional podem lutar igualitariamente: relações de poder (ex.: um solicitante, não satisfeito com a resposta e/ou do comportamento linguístico de seu interlocutor/informante, se identifica socialmente como uma pessoa de status hierárquico superior, a fim de obter uma resposta satisfatória e/ou modificar o comportamento linguístico do destinatário); particularidades culturais (ex.: pessoas idosas rompem códigos sociais e frequentemente não sofrem consequências devido ao fator etário) são algumas das razões que fundamentam essa desigualdade.

Em suma, a troca de informações constitui uma das inúmeras formas de interação verbal e como tal, se desenvolve segundo esquemas preestabelecidos e obedece a regras de procedimento que geram um sistema de direitos e deveres. Como em outros tipos de troca, seus participantes esperam um do outro que cada um contribua/coopere de maneira racional à interpretação de seus enunciados, respeitando o contrato de cooperação que os une. Em caso de conflito, real ou pressentido, cada um objetiva preservar sua face: a prática da polidez aparece, assim, como uma estratégia conciliadora sólida. Esta não deve, todavia, se limitar a um repertório de fórmulas, mas englobar todos os aspectos do discurso. Concomitantemente, parte-se do princípio que cada um almeje dar a melhor imagem de si próprio.

A aplicação do método observação participante a esse cenário interativo possibilita verificar e avaliar todos esses aspectos da troca e apresentar um esboço do perfil sociodiscursivo de seus participantes.

\subsection{Descrevendo e argumentando a hipótese}

Tomando por base a troca de informações em contexto francófono, a-hipótese é que há rompimento do contrato interacional inicial quando o locutor/informante emprega a sequência je ne sais pas moi, a qual indica bem mais do que a negação absoluta e que acarreta, portanto, consequências sociointerativas desfavoráveis ao bom funcionamento da troca verbal.

Para descrever e argumentar essa hipótese, o ponto de partida é o seguinte esquema: 
(1) -Vous savez où se trouve....?/Você sabe onde fica...?

$$
\begin{aligned}
& \text { 1a - Oui } \rightarrow \text { je sais./Sim } \rightarrow \text { Sei. } \\
& \text { 1b - Non } \rightarrow \text { je ne saispas./Não } \rightarrow \text { Não sei. }
\end{aligned}
$$

Em circunstancias ordinárias a informação dada em 1a como em $1 \mathrm{~b}$ é suficiente ( $\operatorname{sim} /$ não), de acordo com a máxima de quantidade; essas informações são verídicas (parte-se do princípio que o informante não tem razões para dissimular a verdade), de acordo com a máxima de qualidade; as informações são pertinentes, de acordo com a máxima de relação; por fim, as informações dadas são claras e concisas, de acordo com a máxima de modo. As repostas 1a como 1b priorizam a função informativa do discurso, asseguram a eficácia da troca e são, consequentemente, conformes ao Princípio de Cooperação.

No entanto, neste tipo de interação, como em outros, a questão relacional (ou "relacionamento interpessoal") comporta a questão identitária. Numa interação, além de assumirem - ou não - um papel preciso/ estereotipado por cada cultura, os participantes trazem com eles seu vivido (físico, social, psicológico). Muitas vezes as particularidades/diferenças identitárias se sobrepõem à função comunicativa e orientam os participantes de acordo com suas necessidades e/ou exigências da situação de troca, nas negociações como na organização de lugares no espaço interativo. Em caso de conflito - real ou pressentido - os participantes podem vir a adotar um comportamento linguístico incompatível com o princípio de polidez.

Para ilustrar esses propósitos consideremos:

(1) - Vous savez où se trouve...?/Você sabe onde fica...?

1c - Moije sais. / Eu, eu sei. ${ }^{10}$

1d - Je sais moi/Eu sei, eu.

1e - Moi je ne sais pas/Eu, eu não sei.

1f - Je ne sais pas moi/Eu não sei, eu.

No que diz respeito a 1c e 1e, além de seu papel de retomada de.../ resposta a..., estas sequências têm frequentemente um valor de contraste. Assim, ao enunciar (1c,1e) o locutor estabelece um contraste com aquele que

10 Traduções literais. 
enuncia (1a, 1b). Simultaneamente, 1c e 1e ecoam ideias/posicionamentos do tipo (1c) "os outros não sabem" ou "os outros pensam que eu não sei enquanto que eu sei"; (1e) "os outros pensam que eu sei enquanto que eu não sei”.

Quanto aos redobramentos pronominais à direita, a saber (1d) Je sais, moi./Eu sei, eu e (1f) Je ne sais pas moi./Eu não sei [,] eu, essas DD suj-locutor também podem estabelecer um contraste com 1a-1c. Em todos esses casos, ao enunciar (1d e 1f) o locutor diz algo mais que sim/não: ele estabelece um contraste e mostra seu contentamento (1d) ou seu aborrecimento (1f). Consequentemente, $1 \mathrm{~d}$ e $1 \mathrm{f}$ possuem uma função emotiva.

Numa abordagem dialógica, estes movimentos de emoções podem ser motivados pelas seguintes vozes:

- a minha resposta foi negativa (je ne sais pas / eu não sei) mas meu interlocutor insiste (ex.: "você tem certeza?"), então eu respondo je ne sais pas moi/eu não sei, eu.

- alguém me faz a mesma pergunta pela enésima vez e então eu respondo "je ne sais pas moi/eu não sei, eu".

- alguém me faz uma pergunta pela primeira vez, talvez eu conheça a resposta, mas respondo "je ne sais pas moi/eu não sei, eu".

Nestes três casos, ao enunciar (1f) o locutor estabelece sua posição na interação, expressa seu desejo de pôr um fim na conversa e, desse modo, se distancia da troca.

Para desenvolver/ilustrar/argumentar estes propósitos, mostro no que segue como a negação aciona conflitos e veicula emoções. Em seguida, discuto o posicionamento de Brown e Levinson (1987), segundo o qual cada membro adulto competente da sociedade tem uma imagem de si que ele tenta impor/fazer aparecer/fazer valer nas interações e que esta imagem, a face, tem dois aspectos complementares:

- a face negativa, ligada à esfera privada, ao sentimento de independência e liberdade de ação;

- a face positiva, cobrindo a necessidade narcisista de ser socialmente reconhecido e valorizado.

Através dessa abordagem emergem traços do perfil dos locutores/ informantes em francês. 


\subsubsection{A negação: acionando conflitos}

Os extratos analisados neste estudo apontam a negação como o elemento linguístico responsável pela transformação da situação inicial. Ou seja, uma situação de troca evolui/se transforma a partir da reposta negativa à pergunta formulada. Face à negação, observa-se que a estratégia mais comumente utilizada para preservar as relações sociais é o par de pedidos de desculpas-perdão, como ilustrado no extrato que segue.

Situação I: (A) um solicitante entra num escritório de informações turísticas e se endereça à informante/atendente (B).

A: Bonjour. Y a-t-il un bureau de tabac dans le quartier?'Tem uma tabacaria neste bairro?

B: Je ne sais pas monsieur. Eu não sei senhor.

A: Peut-être un bar où on peut acheter des cigarettes? Talvez um bar onde se possa comprar cigarros?

B: Je suis désolée, monsieur. Je ne peux pas vous aider, je ne suis pas du quartier. Sinto muito senhor. Eu não posso ajudá-lo, não sou desse bairro.

A: Iln'y pas de soucis. Merci quand même. Au revoir. Não tem problema. Obrigada assim mesmo. Adeus.

Na situação acima, A solicita informações que não somente não fazem parte do script de B (a troca acontece num escritório de informações turísticas), mas que B também não possui. Portanto, sua resposta é negativa (em adequação com o Princípio de Cooperação). Todavia, face à insistência de A, B pede desculpas/perdão ("Je suis désolée. Sinto muito") e se justifica por não ter a informação solicitada (argumentando não morar no bairro onde trabalha). O recurso a este par estratégico tanto permite ilustrar o desejo (verdadeiro ou simulado) em servir outrem quanto evitar conflitos (B não obteve resposta à sua pergunta, mas agradece $\mathrm{A}$ e se despede de forma polida).

Já em outras situações de troca, na ausência de tentativas de cooperação de ambas as partes, o conflito e a degradação da relação entre os participantes são inevitáveis. Tal é o caso da situação (II), na qual a estratégia utilizada é o par acusação-defesa/justificativa.

A situação (II) de troca acontece num centro administrativo (órgão governamental), na sessão de pedidos de visto de residência, entre (A) o 
acompanhante de uma solicitante de visto e (B) a funcionária do balcão de informações.

A: Bonjour madame. Est-ce que madame Untel est arrivée? Bom dia. A senhora Fulana já chegou?

B: Je ne sais pas monsieur. Não sei senhor.

A: Savez-vous si elle est dans son bureau? A senhora sabe se ela está em seu escritório?

B: Je ne sais pas monsieur. Não sei senhor.

A: Vous ne savez pas ou vous ne voulezpas me renseigner? Parce que sa porte est là juste derrière vous, madame. A senhora não sabe ou não quer me informar? Porque a porta (do escritório dela) fica bem aí, atrás da senhora.

B: Oui, peut-être monsieur mais, voyez-vous, je n'aipas que ça à faire, surveiller madame Untel. Si vous voulez lui parler, appelez ce numéro monsieur et demandez un rendez-vous. Sim, talvez senhor, mas, veja só, eu tenho outras coisas para fazer ao invés de observar a senhora Fulana. Se o senhor quiser falar com ela, ligue para esse número e marque um encontro.

Como vemos, A está convencido da má vontade de B em cooperar na troca; A contesta as duas respostas negativas de $\mathrm{B}$ se apoiando em elementos extralinguísticos: a porta do escritório da pessoa solicitada fica atrás do balcão onde se encontra B, o que leva $A$ a deduzir que seria impossível B não estar a par das idas e vindas da colega. Face a este argumento incontestável, para se defender e salvar sua face, B utiliza uma estratégia concessiva. Primeiramente B admite como verdadeira a realidade do que é dito por A para em seguida apresentar este argumento como fraco, em comparação aos argumentos que ela introduz por mais/mas... (ela não é a secretária da senhora Fulana, ela tem outras tarefas a cumprir). A partir daí poder-se-ia concluir que qualquer que seja a situação, B não tem nenhuma obrigação em contribuir à troca; B se apresenta como uma pessoa ocupada que está sendo importunada, o que desvaloriza a face de A. Por fim, ao preconizar conselhos (ex.: telefone/marque um encontro) B intensifica tanto a desvalorização da face de A quanto o caráter impolido de seu comportamento linguístico (ou seja: emprego de formas verbais imperativas). 
Se nos extratos acima é possível identificar a negação como o gatilho da transformação da situação inicial, já em outros casos a identificação de elementos estratégicos que corrompem o Princípio de Cooperação se revela mais complexa. Com efeito, a impolidez linguística pode se manifestar de diversas outras maneiras, sendo uma delas, como sublinhado, o emprego de enunciados emotivos.

\subsection{Veiculando emoções}

Situação (III): no balcão de uma empresa de ônibus. A passageira (A) se endereça à recepcionista (B). "A" aponta para um dos ônibus que se encontra estacionado na plataforma.

A: Est-ce que ce bus s'arrête en ville, près du casino? Esse ônibus para na cidade, perto do casino?

B (1): Je ne sais pas, madame. Je ne connais pas les trajets des bus. Não sei senhora. Não conheço os trajetos dos ônibus.

A: Vous savez tout de même s'il fait des arrêts en ville? Você, pelo menos, dizer/informar se ele para na cidade?

B (2): Je ne sais pas moi c'est au chauffeur qu'il faut demander ou alors [a recepcionista aponta para o painel de informações] regardez là, tout est là. Eu não sei, eu. A senhora deve perguntar para o motorista ou então olhe ali, todas as informações se encontram ali.

Em (III), o pressuposto de base é que a resposta negativa em B (2) consiste em uma reorganização de construções sintáticas canônicas esperadas, do tipo je ne sais pas $\rightarrow$ je ne sais pas non plus/ eu não sei $\rightarrow \mathrm{eu}$ também não sei, cujo valor é basicamente informativo. Ao reativar a forma pronominal desmotivada je, através de sua variante tônica moi, o falante (aqui, a informante) espera conferir um grau maior de eficácia à comunicação e à argumentação (1). Em outras palavras, em (2), a recepcionista enuncia seu aborrecimento: "eu já disse que não sei; que não conheço os trajetos dos ônibus mas já que você insiste: pergunte ao motorista ou então consulte os horários afixados que se encontram bem aí na sua frente". O mesmo acontece na situação (IV):

Situação IV. No balcão de uma companhia ferroviária. 
A: Bonjour. Il vous reste encore des places dans le train de nuit? Bom dia. Ainda há lugares [disponíveis] no trem noturno?

B (1): Je ne sais pas. Le système [informatique] est en panne. Não sei. O sistema [informático] está em pane.

A: Bon alors vous pensez.qu'on peut [y] monter etpuis voir ça avec le contrôleur? Bem então a senhora acha que a gente pode subir [no trem] e resolver isso depois com o fiscal?

B (2): Je ne sais pas moi. Ne me faites pas dire ce que je n'ai pas dit. Si vous prenez le train sans votre billet c'està vos risques et périls. Eu não sei. Não me faça dizer o que eu não disse. Se vocês subirem no trem sem passagens, é problema de vocês.

Como vemos, o que foi dito sobre a situação III em B (2) é aplicável à situação IV em B (2). Nos dois casos, a sequência negativa introduz complementos de informação cuja função principal é a de desresponsabilizar o falante, visto que nenhum desses complementos está diretamente relacionado à pergunta formulada. Com efeito, em IV-B (2) o que a informante deixa claro é não querer ser implicada na decisão do passageiro.

Nas análises das situações acima (I, II, III e IV), apresentou-se argumentos suscetíveis de mostrar que numa troca de informações, uma resposta negativa pode acionar conflitos. Ressaltou-se três tipos de situações: enquanto em alguns casos, para evitar possíveis impasses, os participantes da troca: (i) negociam uma solução; ou (ii) observa-se a ausência de qualquer tentativa de colaboração. Nesses casos, observei que o papel desempenhado por cada um dos participantes da troca vai além do estereótipo social, ou seja, o papel identitário sobrepõe muitas vezes ao seu papel na interação. Considerando, no entanto, o contrato que une os participantes, notou-se também que (iii) em certos contextos, o participante recorre a uma estratégia escapatória, ou seja, ao emprego de enunciados emotivos. E, embora "o desencadeamento do estado emocional [...] colo[que] [o participante] em contato com uma sanção social que culminará em julgamentos diversos de ordem psicológica ou moral" (CHARAUDEAU, 2010, p. 30), aquele que enuncia je ne sais pas moi parece estar pronto a correr o risco. Para tanto, notamos que o locutor procede da seguinte maneira: 
- A DD suj-locutor comportando uma negação (a) quase nunca é utilizada como resposta imediata à uma pergunta formulada; tratase de uma estratégia susceptível de mostrar que o comportamento emotivo do locutor, seu sentimento de aborrecimento, decorre na verdade do comportamento linguístico do interlocutor (por ex.: sua insistência, o que leva a pensar que ele duvida da veracidade do que foi dito);

- a DD suj-locutor comportando uma negação (b) é frequentemente seguida de proposições comportando as mais diversas explicações que aparecem, num primeiro tempo, como argumentações que sustentem a reposta negativa, ilustrando um último esforço (real ou simulado) de colaboração do locutor. $\mathrm{Na}$ verdade, trata-se aí de uma estratégia que permite ao locutor uma grande liberdade de expressão. Em outras palavras, je ne sais pas moi seguido de explicações permite ao locutor "dizer o que bem entende": o que me leva a postular sobre seu valor modal. Para salvar sua face, o locutor-informante recorre a uma estratégia escapatória, ou seja, ao emprego de enunciados emotivos.

\section{Conclusão}

Neste trabalho fundamentado na linguística aplicada foi abordada a questão das emoções no discurso, apoiando-se em situações interacionais de troca verbal de informações face a face, observadas e recolhidas em contexto francófono (França) segundo a metodologia observação participante. A partir desse corpus, levantamos e argumentamos a hipótese de que nessa cena interativa o locutor - o informador francês - se mostra aborrecido quando seu interlocutor-solicitante, não satisfeito com uma resposta negativa, prossegue reformulando a pergunta ou formulando novas perguntas. Consideramos, assim, a negação como o elemento acionador do conflito, e a sequência deslocada comportando uma duplicação do pronome pessoal da primeira pessoa à direita do núcleo verbal como o traço linguístico da atitude aborrecida do locutor-informante. A hipótese aqui defendida evocou o funcionamento sintático emotivo do fenômeno sintático da deslocação, o que possibilitou a visão de como os participantes de uma situação interativa mobilizam emoções em seu discurso com uma finalidade argumentativa. 
Ao enunciar je ne sais pas moi o locutor francês faz uma escolha entre um conjunto de escolhas e mostra que a emoção não é redutível a uma sensação, mas que é de ordem intencional: seu objetivo é fazer com que o interlocutor entenda que a troca verbal chegou ao fim. Ele demonstra assim ter conhecimentos sobre as vantagens (cf. fim da troca) como sobre inconvenientes (cf. atitude impolida) da sua escolha. Sua racionalidade está ligada à crença de que por já ter respondido "não", o interlocutor insiste, logo, é ele o impolido. E é isso que faz desencadear seu estado emocional, o que o coloca em contato com uma sanção social (cf. rompimento do contrato de cooperação) que culmina em julgamentos diversos de ordem psicológica ou moral (cf. a impolidez). Conclui que esse locutor está pronto a correr o risco: trata-se de uma imagem que ele tem de si e que ele tenta impor/fazer aparecer/fazer valer nas interações e que esta imagem, sua face, reveste dois aspectos complementares:

- a face negativa, ligada à esfera privada, ao sentimento de independência e liberdade de ação;

- a face positiva, cobrindo a necessidade narcisista de ser socialmente reconhecido e valorizado.

O perfil esboçado neste trabalho merece ser explorado à luz de outras disciplinas (cf. a sociologia, antropologia, história social) a fim de evidenciar de que maneira (ess)as representações sociais de cada um estão ligadas aos mecanismos sociais.

\section{Agradecimentos}

A pesquisa de que decorre este estudo contou com o apoio da University of Cape Town (UCT), África do Sul.

A versão final deste artigo beneficiou dos conselhos de redação da professora Sílvia Maria Duarte Araújo (Língua portuguesa - Brasil), a quem agradecemos calorosamente. 


\section{Referências}

ANSCOMBRE, J. C.; DUCROT, O. L'argumentation dans la langue. Bruxelles: Mardaga, 1997.

APOTHÉLOZ D. Les dislocations à gauche et à droite dans la construction des schématisations. In: MIÉVILLE, D.; BERRENDONNER, A. Logique, discours et pensée: mélanges offerts à Jean-Blaise Grize. Berne: Peter Lang, 1997. p. 183-217.

ARISTÓTELES. Retórica. Tradução de Manuel Alexandre Júnior. 2. ed. Lisboa: Imprensa Nacional-Casa da Moeda, 2005. Disponível em: https:/ / bit.ly/2JW5bAp. Acesso em: 4 jan. 2019.

BLASCO-DULBECCO, M. Les dislocations en français contemporain: étude syntaxique. Paris: Honoré Champion, 1999.

BENVENISTE, E. Problèmes de linguistique Générale. Paris: Gallimard, 1974 [Problemas de Lingǘstica Geral I. 3.ed. Tradução de Maria da Glória Novak; Maria Luisa Neri. Campinas: Pontes, 1991].

BENVENISTE, E. Problemas de Linguística Geral II. Tradução de Eduardo Guimarães. Campinas: Pontes, 1989.

BOGDAN, R., TAYLOR, S. J. Introduction to Qualitative Research Method: A Phenomenological Approach to Social Sciences. New York: John Wiley \& Sons, 1975.

BROWN, P.; LEVINSON, S. C. Politeness: Some Universals in Language Usage. Cambridge: Cambridge University Press, 1987. Doi: https://doi.org/10.1017/ CBO9780511813085

CECCHETTO, C. A. Comparative Analysis of Left and Right Dislocation in Romance. Studia Linguistica, New York, v. 53, n. 1, 1999. Disponível em: https:/ / bit.ly/2MwgK3s. Acesso em: 4 jan. 2019. Doi: https://doi.org/10.1111/14679582.00039

CHARAUDEAU, P. A patemização na televisão como estratégia de autenticidade. In: MENDES, E.; MACHADO, I. L. As emoções no discurso. Campinas: Mercado das Letras, 2010. p. 23-57. v. 2.

CHOMSKY, N. Syntactic Structures. The Hague: Mouton, 1957.

CHOMSKY, N. Lectures on Government and Binding. Dordrecht: Foris, 1981.

CHOMSKY, N.; LASNIK, H. Principles and Parameters Theory, in Syntax: An International Handbook of Contemporary Research. Berlin: de Gruyter, 1993.

CHOMSKY, N. The Minimalist Program. Massachusetts: The MIT Press, 1995. 
CIGADA, S. Les émotions dans le discours de la construction européenne. Milano: Università Cattolica del Sacro Cuore, 2008.

DE OLIVEIRA, P. A expressão linguística de emoções: um estudo discursivo do sentimento de aborrecimento na troca de informações em contexto francófono. 2014. 60f. Tese (Pós-Doutorado em Linguística Aplicada) - Faculdade de Letras, Universidade de São Paulo, São Paulo, 2014. Disponível em: https:/ / bit. ly/2WFsZi7. Acesso em: 31 maio 2019.

DE OLIVEIRA, R. The relationship between negation and impoliteness in the exchange of information in French. Alfa-Revista de Linguistica, Araraquara, v. 29, 2015. Disponível em: https://bit.ly/2ESK7qk. Acesso em: 31 maio 2019.

DUCROT, O. Les lois du discours. Langue française, Paris, n. 42. p. 21-33, 1979. Doi: https://doi.org/10.3406/lfr.1979.6152

DUCROT, O. O dizere e o dito. Tradução de Eduardo Guimarães. Campinas: Pontes, 1987.

DUFRESNE, M. Etude diachronique de la cliticisation des pronoms sujets à partir du français médiéval. Revue Québécoise de Linguistique, Montreal, v. 24, n. 1, p. 83109, 1995. Doi: https://doi.org/10.7202/603104ar. Disponível em: https://bit. ly/2Wl3YcC. Acesso em: 4 jan. 2019.

ELSTER, J. Rationalité, émotions et norms sociales. In La couleur des pensées. Paris: EHESS. 1995.

GRICE, H.P. Logic and Conversation. In: Syntax and Semantics, Vol. 3, Speech Acts, ed. by Peter Cole and Jerry L. Morgan. New York: Academic Press 1975, 41-58.

GRICE, H. P. Lógica e conversação. Tradução de João Wanderley Geraldi. In: DASCAL, M. (org.). Fundamentos metodológicos da linguística, 4: pragmática: problemas, críticas, perspectivas da linguística. Campinas: Instituto de Estudos da Linguagem da Unicamp, 1982. p. 81-103.

GOFFMAN, E. Les rites d'interaction. Paris: Editions de Minuit, 1967.

GOFFMAN, E. La mise en scène de la vie quotidienne: tomes 2 \& 3. Paris: Editions de Minuit, 1973.

GOFFMAN, E. Façons de parler. Paris: Edition de Minuit, 1987.

GUMPERZ, J. Discourse Strategies. Cambridge: Cambridge University Press, 1982. Doi: https://doi.org/10.1017/CBO9780511611834

HUANG, C. T. On the Distribution and Reference of the Empty Categories. Linguistic Inquiry, Boston, n. 15, p. 531-74, 1984. 
HUANG, Y. Anaphora: A Cross-Linguistic Approach. Oxford: Oxford University Press, 2000. Disponível em: https:/ / bit.ly/2Z1tvEu. Acesso em: 4 jan. 2019.

HOLMBERG, A. Is There a Little Pro? Evidence from Finnish. Linguistic Inquiry, Cambridge, n. 36, p. 533-564, 2005. Doi: https://doi.org/10.1162/ 002438905774464322

JOBERT, M. L'impolitesse linguistique: vers un nouveau paradigme de recherche? Lexis, Lyon, Spécial 2, p. 5-20, 2010. Doi: https://doi.org/10.4000/lexis.777

KERBRAT-ORECCHIONI, C. L'Énonciation. Paris: A. Colin, 1980.

KERBRAT-ORECCHIONI, C. Les interactions verbales. 3. ed. Paris: A. Colin, 1994. KERBRAT-ORECCHIONI, C. La conversation. Paris: Seuil. 1996.

KERBRAT-ORECCHIONI, C. Análise da conversação: princípios e métodos. Tradução de Carlos Piovezani Filho. São Paulo: Parábola Editorial, 2006 [1999].

KERBRAT-ORECCHIONI, C. L'impolitesse en interaction: aperçus théoriques et étude de cas. Lexis, Lyon, Spécial 2, p. 35-60, 2010. Doi: https://doi.org/10.4000/ lexis.796

LAKOFF, R. The limits of politeness: therapeutic and courtroom discourse. Multilingua, [S. I, v. 8, n. 2-3, p. 102-120, 1989. Doi: https://doi.org/10.1515/ mult.1989.8.2-3.101

LAMBRECHT, K. Information Structure and Sentence Form: Topic, Focus, and the Mental Representations of Discourse Referents. Cambridge: Cambridge University Press, 1994. Doi: https:// doi.org/10.1017/CBO9780511620607

LAPASSADE, G. L'observation participante. In: NARUS-MICHEL, J.; ENRIQUEZ, E.; LÉVY, A. Vocabulaire de Psychosociologie. Toulouse: Eres, 2002. p. 375-390. Doi: https://doi.org/10.3917/eres.barus.2002.01.0375. Disponível em: https://bit.ly/2IhQIf6. Acesso em: 4 jan. 2019.

MARCUSHI, L. A. Análise da conversação. 5. ed. São Paulo: Ática, 1999.

MARCUSHI, L. A. Gêneros textuais emergentes e atividades linguísticas no contexto de novas tecnologias. In: REUNIÃO DO GRUPO DE ESTUDOS LINGÜÍSTICOS DO ESTADO DE SÃO PAULO, 50., 2002, São Paulo. Anais […]. São Paulo: USP, 2002.

MARCUSHI, L. A. Produção textual, análise de gêneros e compreensão. São Paulo: Parábola Editorial, 2008.

MARCUSHI, L. A.; XAVIER, A. C. (org.). Hipertexto e gêneros digitais: novas formas de construção de sentido. 3. ed. São Paulo: Cortez, 2010. 
NØLKE, H. Note sur la dislocation du sujet: thématisation ou focalization? In: KLEIBER, G.; RIEGEL, M. (ed.). Les formes du sens: études de linguistique française, médiévale et générale offertes à Robert Martin à l'occasion de ses 60 ans. Louvain-la-Neuve: Duculot, 1997. p. 281-294. Doi: https://doi.org/10.3917/dbu. kleib.1996.01.0281

PERELMAN, C.; OLBRECHTS-TYTECA, L. Traité de l'argumentation: la nouvelle réthorique. Paris: PUF, 1958.

PLANTIN, Chr. Lieux communs dans l'interaction argumentative. In: PLANTIN, C. (dir.). Lieux communs, topoi, stéréotypes, clichés. Paris: Éditions Kimé, 1993. p. 480-496. PLANTIN, Chr. Arguing emotions. In: INTERNATIONAL CONFERENCE OF THE INTERNATIONAL SOCIETY FOR THE STUDY OF ARGUMENTATION, 4., 1999, Amsterdam. Proceedings [...]. Lyon: Université de Lyon 2, 1999. Doi: https://doi.org/10.3726/978-3-0352-0070-6. Disponível em: http:// rozenbergquarterly.com/issa-proceedings-1998-arguing-emotions/. Acesso em: 13/06/2019.

PLANTIN, Chr. As razões das emoções. In: MENDES, E.; MACHADO, I. L. As emoções no discurso. Campinas: Mercado das Letras, 2010. v. 2. p. 57-80.

PLANTIN, Chr. Les bonnes raisons des émotions: principes et méthodes pour l'analyse de la parole émotionnée. Berne: Peter Lang, 2011.

PLANTIN, Chr.; DOURY, M.; TRAVERSO, V. Les émotions dans les interactions. Lyon: Presses Universitaires de Lyon, 2000.

POLO, C. et al. Quand construire une position émotionnelle, c'est choisir une position argumentative: le cas d'un café débat sur l'eau potable au Mexique. Semen, [S. I, n. 35, p. 41-64, 2013. Disponível em: https://bit.ly/2ZeDnLn. Acesso em: 1 jan. 2019.

REBOUL, A.; MOESCHLER, J. La pragmatique aujourd'bui: une nouvelle science de la communication. Paris: Seuil, 1998.

ROUVILLOIS, F. Histoire de la politesse de la Révolution à nos jours. Paris: Flammarion, 2006.

SACKS, H.; SCHEGLOFF, E.; JEFFERSON, G. Sistemática elementar para a organização da tomada de turnos para a conversa. Veredas, Juiz de Fora, v. 7, n. 1-2, p. 9-73, 2003.

SILVA, C. R.; ANDRADE, D. N. P.; OSTERMANN, A. C. Análise da conversa: uma breve introdução. ReVEL, [S. ], v. 7, n. 13, 2009. Disponível em: https://bit. ly/2WjPyEx. Acesso em: 5 jun. 2019. 
SIMONE, R. Une interprétation diachronique de la dislocation à droite dans les langues romanes. Langue Française, Paris, n. 115, p. 48-61, 1997. Doi: https://doi. org/10.3406/lfr.1997.6221

SOULÉ, B. Observation participante ou participation observante? Usages de la notion de participation obervante en sciences sociales. Recherches Qualitatives, Montreal, v. 27, n. 1, p. 127-140, 2007.

TOULMIN, S. The uses of arguments. Cambridge: Cambridge University Press, 1958.

WALTON, D. The place of emotions in argument. Philadelfia: Pennsylvania State University Press, 1992.

WAUTHION, M.; SIMON, A. C. Politesse et idéologie: rencontres de pragmatique et de rhétorique conversationnelles. Louvain: Peeters Publishers, 2000.

Data de submissão: 04/01/2019. Data de aprovação: 30/05/2019. 